\title{
Synthesis of Verbenols and Related Alcohols and Their PMR Spectra with Shift Reagent*
}

\author{
Chikao Nishino and Hisao TAKayanagi \\ Mitsubishi-Kasei Institute of Life Sciences, 11 Minamiooya, \\ Machida-shi, Tokyo 194, Japan \\ Received May 24, 1979
}

\begin{abstract}
In connection with our investigation on the structure-activity relationships of the American cockroach sex pheromone mimic. (+)-trans-verbenyl acetate, a number of alcohols having 6, 6dimethylbicyclo[3.1. 1]heptane skeleton were synthesized, and measured their PMR spectra in the presence of the shift reagent, $\mathrm{Eu}(\mathrm{dpm})_{3}$. The induced shifts of the 6,6-gem-dimethyl protons and $\alpha$-proton at the $\mathrm{C}-7$ guided us to distinction between cis-and trans-alcohol. The configuration of secondary methyl groups was discussed from the induced shift values of the methyl protons.
\end{abstract}

The typical sexual behavior of the male American cockroach (Periplaneta americana L.) to the female sex pheromone was characterized as consisting of wing flutter, extention of the abdomen and attempted copulation. ${ }^{1}$ The structural elucidation of the pheromone, periplanone-B, was carried out by Persoons et al. ${ }^{2}$. who reported the structure to be a sesquiterpenoid possessing a germacrane skeleton. On the other hand, Bowers et $a l^{3}{ }^{3}$ discovered that $(+)$-bornyl acetate (bicyclic monoterpenoid) and three other plant-derived compounds excite males of the American cockroach showing the typical sexual response mentioned above. Quite recently, Nishino et al. ${ }^{4}$ carefully bioassayed about twenty bicyclic monoterpenoids and found (+)-transverbenyl acetate and (-)-bornyl acetate as sex pheromone mimics of the insect.

We had a simple question why such monoterpenoids and the sesquiterpenoid sex pheromone cause the same sexual excitement. In order to solve the question, the structural key factors for the sexual activity have been investigated for the monoterpenoid mimics. We speculated from inspection of molecular model of the mimics that the distances among the acetate and geminal dimethyl groups in the active

* Studies on the Sex Pheromone Mimic of the American Cockroach, (+)-trans-Verbenyl Acetate. Part I. bornyl acetates and verbenyl acetate are significant for the activity. ${ }^{5}$ This might be extended to that some special moieties and their stereo-interaction play key roles for causing the activity. Biological assay data with many analogs are, however, required in order to give more accurate informations. Hence, verbenols and related alcohols which would be mother compounds of active mimics were synthesized as our first approach. Because the position and orientation of the acetoxyl and single methyl groups of the mimic, $(+)$-transverbenyl acetate, are considered to be important for the sexual activity, ${ }^{5}$ the position of a hydroxyl group was fixed at the $\mathrm{C}-2$ and a secondary methyl or methylene group was introduced to the $\mathrm{C}-3$ or $\mathrm{C}-4$ in our compounds as shown in Fig. 1.

Our efforts were directed to the formation of the corresponding ketones as the key compound to the alcohols. In reduction of the ketones, lithium aluminum hydride $\left(\mathrm{LiAlH}_{4}\right)$ was basically employed in giving the cis alcohols, whereas lithium-ammonia (Birch reduction) in the trans alcohols, on the basis of the fact that $\mathrm{LiAlH}_{4}$ and Birch reduction were used to obtain isoborneol ${ }^{7}$ and borneol ${ }^{7)}$ from camphor, respectively. When both methods were unsuccessful, Meerwein-Ponndorf reduction was performed. Synthetic routes carried out according to the above basic ideas are il- 

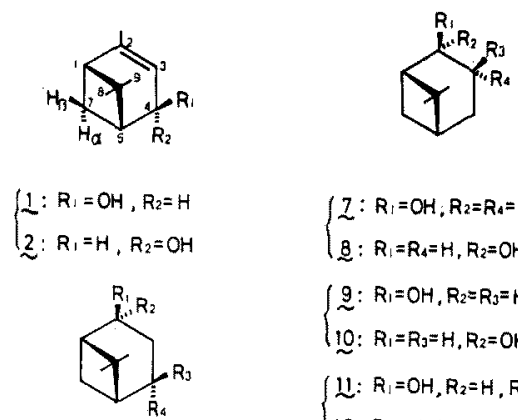

$\left\{\begin{array}{l}Z: R_{1}=\mathrm{OH}_{,} \mathrm{R}_{2}=\mathrm{R}_{4}=H_{i}, \mathrm{R}_{3}=\mathrm{CH}_{3} \\ \text { g: }: \mathrm{R}_{1}=\mathrm{R}_{4}=H_{1} \mathrm{R}_{2}=\mathrm{OH}, \mathrm{R}_{3}=\mathrm{CH}_{3}\end{array}\right.$ 2: $\mathrm{R}_{1}=\mathrm{OH}, \mathrm{R}_{2}=\mathrm{R}_{3}=\mathrm{H}, \mathrm{R}_{4}=\mathrm{CH}_{3}$ 10: $R_{1}=R_{3}=H, R_{2}=O H, R_{4}=C_{3}$ 1L: $R_{1}=\mathrm{OH}, \mathrm{R}_{2}=\mathrm{H}, \mathrm{R}_{\mathrm{s}} \cdot \mathrm{R}_{4}==\mathrm{CH}_{2}$

寻: $\mathrm{R}_{1}=\mathrm{OH}, \mathrm{R}_{2}=\mathrm{R}_{4}=\mathrm{H}_{2} \mathrm{R}_{3}=\mathrm{CH}_{3}$

运: $R_{1}=R_{4}=H, R_{2}=O H, R_{3}=C_{3}$

$\left\{\begin{array}{l}5: R_{1}=\mathrm{OH}, \mathrm{R}_{2}=\mathrm{R}_{3}=\mathrm{H}, \mathrm{R}_{4}=\mathrm{CH}_{3} \\ 6: \mathrm{R}_{1}=\mathrm{R}_{3}=\mathrm{H}, \mathrm{R}_{2}=\mathrm{OH}, \mathrm{R}_{4}=\mathrm{CH}_{3}\end{array}\right.$

FIG. 1.
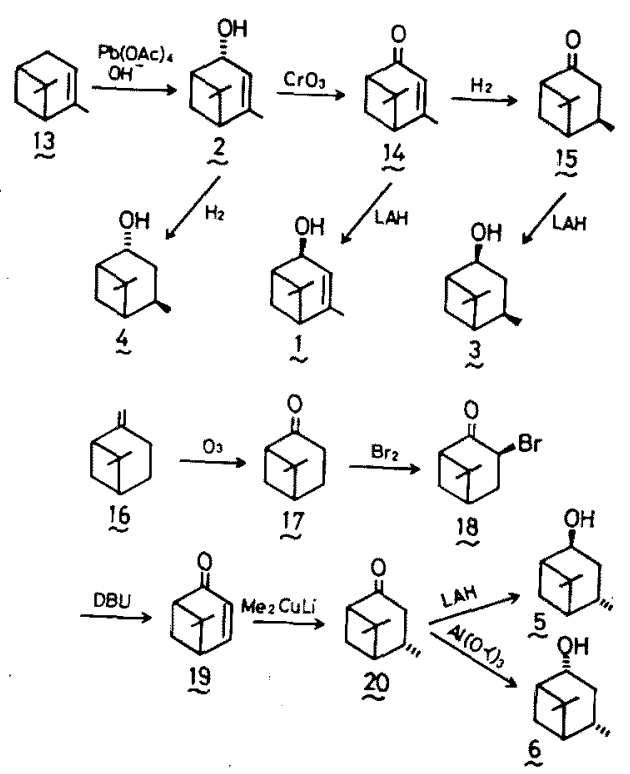

SCHeME 1.

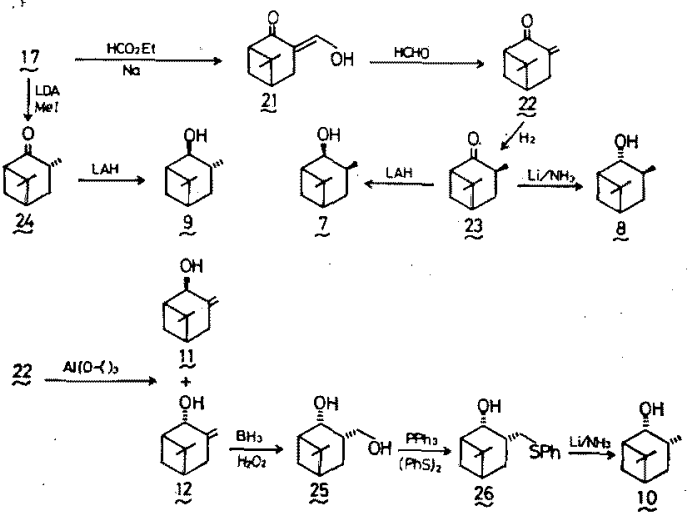

SCFEME 2. lustrated in Schemes 1 and 2.

$(+)$-cis-Verbenol ${ }^{* 1}(\mathbf{1}), \operatorname{mp} 69 \sim 70^{\circ},[\alpha]_{\mathrm{D}}+$ 9.6 $6^{\circ}$ [chloroform $\left.\left(\mathrm{CHCl}_{3}\right)\right]^{* 2}, \quad(+)$-transverbenol $(2),[\alpha]_{D}+130.0^{\circ}\left(\mathrm{CHCl}_{3}\right)$, and $(+)-$ verbenone $(\mathbf{1 4}),[\alpha]_{\mathrm{D}}+240.1^{\circ}\left(\mathrm{CHCl}_{3}\right)$, were obtained from $(+)$ - $\alpha$-pinene $(13),[\alpha]_{D}+46.9^{\circ}$ (neat), as per Mori et al. ${ }^{8)}$ Catalytic hydrogenation of 2 and 14 afforded (+)-isoverbanol (4), mp $61 \sim 64^{\circ},[\alpha]_{\mathrm{D}}+43.8^{\circ}$, and cis-verbanone (15), $\mathrm{PMR}^{* 3}: 1.17$ (3H, d, $\left.J=7.0,4 \beta-\mathrm{Me}\right)$, respectively. The $\mathrm{LiAlH}_{4}$ reduction of 15 gave $(+)$ - neoisoverbanol (3), $\mathrm{mp} 68 \sim 69.5^{\circ}$, $[\alpha]_{\mathrm{D}}+9.0^{\circ}$.

To the bromination of $(+)$-nopinone (17), $[\alpha]_{D}+12.3^{\circ}$, prepared from $(-)$ - $\beta$-pinene (16), $[\alpha]_{\mathrm{D}}-21.0^{\circ}$ (neat), reaction temperature fairly affected, $i . e$, in the case at $0^{\circ}$, major resultant was $3 \alpha$-bromonopinone $\left(\mathbf{1 8}^{\prime}\right)$, whereas at room temperature (r.t.) major product was $3 \beta$ bromonopinone (18). In the PMR of 18 and $18^{\prime}$, the chemical shifts of the $3-\mathrm{H}$ suggested the orientation of bromo moiety; $3 \alpha-\mathrm{H}$ (18) resonated at 4.82 , while $3 \beta-\mathbf{H}\left(\mathbf{1 8}^{\prime}\right)$ which is shielded by the C -9 methyl group at 4.39 .

Dehydrobromination with 1,8-diazabicyclo [5. 4. 0]-7-undecene (DBU) was undergone to 18, and the resulting apoverbenone (19) was immediately methylated with lithium dimethylcuprate $\left(\mathrm{Me}_{2} \mathrm{CuLi}\right)$ to give trans-verbanone (20). Protons of the introduced secondary methyl group with $\alpha$ configuration resonated at a higher field (1.05) than that of $4 \beta$-methyl group of 15 (1.17). On $\mathrm{LiAlH}_{4}$ and MeerweinPonndorf reduction, 20 yielded (-)-neoverbanol (5); $\mathrm{mp} 76.5 \sim 77^{\circ},[\alpha]_{\mathrm{D}}-16.5^{\circ}$, and (+)verbanol $(6), \mathrm{mp} 56 \sim 57^{\circ},[\alpha]_{\mathrm{D}}+8.4^{\circ}$, respectively.

3-Methylenenopinone (22) which is a key

*1 For trival names, refer to: D.V. Banthorpe and D. Whittaker, Chem. Rev., 66, 643 (1966).

*2 Specific rotations were measured in benzene at $25^{\circ}$ (Union automatic polarimeter PM-201), unless otherwise stated.

*3 PMR spectra were taken in deuteriochloroform at $60 \mathrm{MHz}$ (Hitachi $\mathrm{R}-24$ ), unless otherwise noted. Chemical shifts are expressed in ppm tetramethylsilane, and coupling constants $(J)$ in $\mathrm{Hz}$. Singlet, doublet, triplet and multiplet are abbreviated to s, d, t, and $\mathrm{m}$, respectively. 
compound for introducing $\mathrm{C}_{1}$ unit to the $\mathrm{C}-3$ of the skeleton was prepared from nopinone (17) following the procedure by BessièreChrétien. ${ }^{9)}$ Catalytic hydrogenation of $\mathbf{2 2}$ afforded $3 \beta$-methylnopinone (23) with a trace amount of its epimer (24). With lithium diisopropylamide (LDA) and methyl iodide (MeI), 3 $\alpha$-methylnopinone (24) was obtained from 17. Configuration of the 3-methyl groups of $\mathbf{2 3}$ and 24 was established by the chemical shift of the $\mathrm{C}-9$ methyl proton according to Bessière-Chrétien's data ${ }^{9)}$ $[0.70(3 \mathrm{H}, \mathrm{s})$ in 23 and $0.90(3 \mathrm{H}, \mathrm{s})$ in 24]. 3-Methylnopinones, 23 and $\mathbf{2 4}$, provided (-)$3 \beta$-methyl-cis-nopinol (7), $[\alpha]_{\mathrm{D}}-0.8^{\circ}$, and $(+)$ -

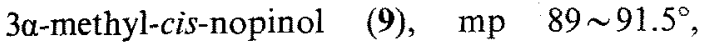
$[\alpha]_{\mathrm{D}}+45.4^{\circ}$, on $\mathrm{LiAlH}_{4}$ reduction, respectively. Birch reduction of 23 gave (-)-3 $\beta$-methyltrans-nopinol $(8), \mathrm{mp} 44 \sim 46^{\circ},[\alpha]_{\mathrm{D}}-62.6^{\circ}$, as a mixture with $7(3: 1)$. Column chromatography with silicic acid was effective in separating them.

Meerwein-Ponndorf reduction of the methyleneketone (22) gave a mixture of cis-and transmethylenenopinol (11 and 12). The ratio of the mixture was seemed to be depend on reaction period. (-)-3-Methylene-trans-nopinol (12), $[\alpha]_{\mathrm{D}}-52.5^{\circ}$, was more abundant than $(+)$ 3-methylene-cis-nopinol (11) mp 59.5 61.5 , $[a]_{\mathrm{D}}+76.6^{\circ}$, after $10 \mathrm{hr}$. The exo methylene group of 12 was converted to a hydroxymethyl group (25), PMR: $3.6 \sim 4.0(2 \mathrm{H}, \mathrm{m})$, on hydroboration $\left(\mathrm{BH}_{3}\right)$-oxidation $\left(\mathrm{H}_{2} \mathrm{O}_{2}\right)$ by the procedure of Bessière-Chrétien. ${ }^{101}$ The diol (25) was derived to monophenylsulfide (26), ${ }^{11}$ PMR: 2.91 ( $1 \mathrm{H}$, double $\mathrm{d}, J=6.0$ and 11.5 ) and $3.35(1 \mathrm{H}$, double $\mathrm{d}, J=8.0$ and 11.5$)$, and was finally reduced to (-)-3 $\alpha$-methyl-transnopinol $(\mathbf{1 0})$, mp $47 \sim 48.5^{\circ},[\alpha]_{\mathrm{D}}-19.2^{\circ}$, In order to get 10, Meerwein-Ponndorf and Birch reduction of $3 \alpha$-methylnopinone (24) were attempted. In either case, however, epimerization of the methyl group occurred, and cisand trans-nopinol with $3 \beta$-methyl group were obtained as the result.

The configuration of secondary methyl groups of compounds, 3-10, was assignable from reaction mechanisms in generation of the methyls.

In catalytic hydrogenation of derivatives of pinenes, verbenone and verbenols, the surface of the catalyst approaches from the less hindered $\alpha$ side of the molecule. ${ }^{21} \quad$ Therefore, all the catalytic hydrogenation products $(4,15$ and 23) in our compounds should have a secondary methyl group with $\beta$ configuration.

The reagent, $\mathrm{Me}_{2} \mathrm{CuLi}$, is known to use for Michael addition. In the reaction from apoverbenone (19) to 4-methylketone (20) using this reagent, which was established by Bessière-Chrétien, ${ }^{9}$ a methyl anion attacks the cationic site at the $\mathrm{C}-4$ of 19 . Since the steric hindrance due to the dimethyl substituted bridge-ring prevents the attack of the anion from $\beta$ side, the secondary methyl at $\mathrm{C}-4$ of $\mathbf{2 0}$ is $\alpha$ configuration. The hindrance is also assumed to be effective to formation of the secondary methyl group of $\mathbf{2 4}$. In the reaction from 17 to $\mathbf{2 4 ,}$ LDA makes an anionic site on the $\mathrm{C}-3$ of nopinone (17) and the site must be attacked by the methyl cation (MeI) from the less hindered $\alpha$ side, so that $3 \alpha$-methylnopinone (24) is made. ${ }^{13)}$

For the $\alpha$ configuration of the secondary methyl of 10 was ascertained by the formation of 24 on Jones' oxidation of 10. This means that a hydroxymethyl group with a configuration was generated in $\mathbf{2 5}$, when $\mathbf{1 2}$ was treated with $\mathrm{BH}_{3}$ and $\mathrm{H}_{2} \mathrm{O}_{2}$. As shown in Fig. 2, BessièreChrétien $^{10)}$ reported that compound 27 produced 28 and $28^{\prime}$ with a ratio of $2: 1$ on the same treatment, in which $\alpha$ attack of a hydride ion was preferable to the other. The formation of the $3 \alpha-h y d r o x y m e t h y l$ group in $\mathbf{2 5}$ seems to
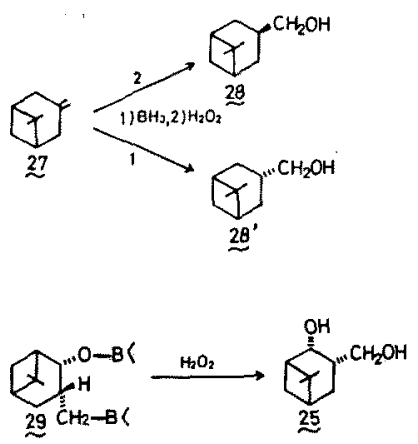

FIG. 2. 
Table I. Chemical Shifts (ppm) of 8- $\mathrm{CH}_{3}, 9-\mathrm{CH}_{3}, 7-\mathrm{H}(\alpha)$ and Secondary $\mathrm{CH}_{8}$ of Pairs of cis-trans Isomers and Induced Shifts ( $(\mathrm{ppm})$ ) OF the Protons on Addition of $\mathrm{Eu}(\mathrm{dpm})_{3}(0.08 \mathrm{mmol})$ To $\mathrm{CDCl}_{3}(0.3 \mathrm{ml})$ SOLUTION OF THE SÜBSTRATES $(0.2 \mathrm{mmol})$ IN THE PMR SPECTRA (100 MHz)

\begin{tabular}{|c|c|c|c|c|c|c|c|c|}
\hline Compound & 9- $\mathrm{CH}_{3}$ & $\underset{(\mathrm{A})}{\Delta \mathrm{ppm}}$ & $8-\mathrm{CH}_{3}$ & $\underset{\text { (B) }}{\text { Appm }}$ & $7-H(\alpha)^{a}$ & $\Delta \mathrm{ppm}$ & $\mathrm{sec}-\mathrm{CH}_{3}^{b}$ & $\Delta p p m$ \\
\hline$(+)$-cis-Verbenol (1) & 1.08 & 3.34 & 1.35 & 1.35 & 1.28 & 1.98 & - & - \\
\hline (+)-trans-Verbenol (2) & 0.88 & 1.42 & 1.35 & 1.10 & 1.32 & 5.31 & - & - \\
\hline$(+)$-Neoisoverbanol (3) & 1.19 & 3.45 & 1.23 & 1.53 & 0.68 & 2.29 & 1.05 & 1.50 \\
\hline$(+)$-Isoverbanol (4) & 1.00 & 1.10 & 1.25 & 0.83 & 1.24 & 3.96 & 1.00 & 0.90 \\
\hline (-)-Neoverbanol (5) & 1.08 & 3.72 & 1.22 & 1.50 & 0.96 & 2.23 & 0.92 & 1.11 \\
\hline$(+)$-Verbanol (6) & 0.80 & 1.36 & 1.25 & 1.11 & 1.61 & 4.67 & 0.92 & 1.48 \\
\hline 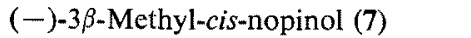 & 1.02 & 3.16 & 1.21 & 1.14 & 1.30 & 1.91 & 1.08 & 3.93 \\
\hline$(-)-3 \beta$-Methyl-trans-nopinol (8) & 0.75 & 1.50 & 1.23 & 0.97 & 1.57 & 4.78 & 1.15 & 3.10 \\
\hline$(+)-3 \alpha$-Methyl-cis-nopinol (9) & 1.09 & 3.20 & 1.23 & 1.20 & 0.73 & 2.23 & 1.17 & 2.16 \\
\hline 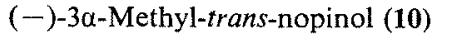 & 0.94 & 1.22 & 1.24 & 0.90 & 1.19 & 4.94 & 1.10 & 4.55 \\
\hline (+)-3-Methylene-cis-nopinol (11) & 1.04 & 3.82 & 1.25 & 1.39 & 0.88 & 2.06 & - & - \\
\hline (-)-3-Methylene-trans-nopinol (12) & 0.84 & 1.32 & 1.26 & 0.99 & 1.23 & 5.26 & - & - - \\
\hline
\end{tabular}

be in conflict with the case of 28 . However, an intermediate 29 may exist in the hydroboration of 12, since it is considered that the steric hindrance of the borane complex of the hydroxyl group at the $\mathrm{C}-2$ obstructs the attach of hydride ion to the $\mathrm{C}-3$ from $\alpha$ side.

The following reports led us to the application of a shift reagent to the PMR spectra of the alcohols to obtain more confirmable proofs for the configurational determination.

In the PMR of isoborneol and borneol, the protons of geminal dimethyl groups $\left(\mathrm{C}-8^{* 4}\right.$ and $(\mathrm{C}-9)$ are influenced showing down-field shifts by addition of $\mathrm{Eu}(\mathrm{fod})_{3}{ }^{14)}$ and $\mathrm{Eu}(\mathrm{dpm})_{3} \cdot{ }^{15}$ ) In comparison of such spectra between isoborneol and borneol, ${ }^{14,15}$ ) the C-8 methyl protons more largely shift to a lower field than the C-9 methyl ones in isoborneol, while both methyl protons show small down-field shifts with nearly same intensity in borneol. Thus, comparative analysis of the induced shifts of the protons of geminal dimethyl groups may be distinguishable between epimeric bicyclic

\footnotetext{
*4 The numbering of bornane is as follows:

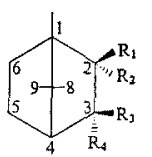
Isoborneol: $\mathrm{R}_{1}=\mathrm{OH}, \mathrm{R}_{2}=\mathrm{R}_{3}=\mathrm{R}_{4}=\mathrm{H}$ Borneol: $\mathrm{R}_{1}=\mathrm{R}_{3}=\mathrm{R}_{4}=\mathrm{H}, \mathrm{R}_{2}=\mathrm{OH}$ endo-Campheniol: $\mathrm{R}_{1}=\mathrm{H}, \mathrm{R}_{2}=\mathrm{OH}, \mathrm{R}_{3}=$ $\mathrm{R}_{4}=\mathrm{CH}_{3}$
}

monoterpene alcohols in the PMR with a shift reagent.

According to this conception, we took the spectra in the $\mathrm{CDCl}_{3}(0.3 \mathrm{ml})$ solution of a mixture of the alcohol and the shift reagent $[\mathrm{Eu}$ $\left.(\mathrm{dpm})_{3}\right]$ at $100 \mathrm{MHz}$ (JEOL PS-100). The ratio of the mixture was changed from 1: 0 to $1: 0.2,1: 0.4$ and $1: 0.6$. Among the ratios, 1: 0.4 [actually $0.2 \mathrm{mmole}$ of the alcohol: 0.08 mmole of $\mathrm{Eu}(\mathrm{dpm})_{3}$ ] was the best in the resolution and the separation of different protons. The PMR results are listed in table $\mathrm{I}$.

As assumed, in the cis alcohols the C-9 methyl protons showed larger down-field shifts (3.16 3.82 ppm, $A$ in the table) than the C-8 methyl protons $(1.14 \sim 1.53 \mathrm{ppm}, B$ in the table ). On the other hand, in the trans alcohols, both $A$ and $B$ values were rather small with a range of $1.0 \sim 1.5 \mathrm{ppm}$, although the $A$ value is slightly larger than the $B$ value. When man considers the situation of the $\mathrm{C}-8$ and C-9 methyl groups against the hydroxyl groups of a pair of cis-tans alcohols, the C-9 methyl group locates most closely to the $\beta$ hydroxyl group in cis-alcohol. This may cause the largest induced shift of the C-9 methyl protons in cis-alcohol, as compared with the other cases.

A distinct sharp doublet $(J=8.7 \sim 8.9)$ 
ascribed to the 7-H( $\alpha)$ has been observed in the PMR spectra of verbenols and verbenone ${ }^{16)}$, and was evidence in our spectra of all compounds reported here $(J=8 \sim 10.5)$. In our compounds, the proton situates below the plane made up of $\mathrm{C}-1-2-4-5$, and is close to $\alpha$ substituent of the $\mathrm{C}-2, \mathrm{C}-3$ and $\mathrm{C}-4$. Accordingly, the 7-H( $\alpha)$ doublet must be more affected by $2 \alpha$-hydroxyl group (trans-alcohol) than $2 \beta$-hydroxyl group (cis-alcohol) in our PMR experiment. In fact, the induced shifts of the doublet signal of $7-\mathrm{H}(\alpha)$ were larger in the trans alcohols $(4 \sim 5 \mathrm{ppm})$ than in the cisalcohols (about $2 \mathrm{ppm}$ ) as shown in the table. This PMR behavior of the 7-H( $\alpha)$ signal after addition of a shift reagent is useful in determining configuration of the hydroxyl group of 6, 6-dimethylbicyclo [3. 1. 1] heptanols.

Configuration of the secondary methyl group seems to be confirmed from its induced shift value in the PMR of $\mathbf{3} \sim \mathbf{1 0}$ by addition of $\mathrm{Eu}(\mathrm{dpm})_{3}$. Sen et al. ${ }^{17)}$ applied $\mathrm{Eu}(\mathrm{dpm})_{3}$ to the PMR of four isomeric 3-aminopinane for their configurational and conformational analyses. In the isomers, secondary methyl groups of $3 \beta$-amino- $2 \alpha \mathrm{H}$-pinane and $3 \alpha$ amino- $2 \beta \mathrm{H}$-pinane showed larger down-field shift than those of the two other isomers on addition of the shift reagent. Furthermore, Paasivirta et al. ${ }^{18)}$ reported that in endo-campheniol (see the footnote in ${ }^{* 4}$ ), the $3 \alpha$-methyl protons more greatly shifted to a lower field than the $3 \beta$-methyl protons when $\mathrm{Eu}(\mathrm{dpm})_{3}$ was used for the PMR spectra. Hence, it is assumable that the methyl group with the same configuration to the vicinally positioned hydroxyl group $(\alpha-\alpha$ or $\beta-\beta)$ is more influenced by shift reagents than the group with the opposite relationships $(\alpha-\beta, \beta-\alpha)$.

In our alcohols possessing a vicinal secondary methyl-hydroxyl group $(7 \sim \mathbf{1 0})$, larger induced shifts of the secondary methyl protons were observed for the compounds having $\alpha-\alpha(10,4.55)$ and $\beta-\beta(7,3.93 \mathrm{ppm})$ relationships in comparison with the compounds having $\alpha-\beta(9,2.16)$ and $\beta-\alpha(8,3.10)$ relationships. Moreover, the similar trend was observable in the alcohols with a 1,3 relation be- tween the two groups $(3 \sim 6)$. The secondary methyl protons shifted to a lower field in $\mathbf{6}$ $(4 \alpha-\mathrm{Me}, 2 \alpha-\mathrm{OH} ; 1.48)$ and $3(4 \beta-\mathrm{Me}, 2 \beta-\mathrm{OH}$; 1.50) with larger induced shifts than those in 5 $(4 \alpha-\mathrm{Me}, 2 \beta-\mathrm{OH} ; 1.11)$ and $4(4 \beta-\mathrm{Me}, 2 \alpha-\mathrm{OH}$; $0.90 \mathrm{ppm}$ ).

Thus, informations from the PMR spectra added a shift reagent are very valuable for the stereochemical elucidation of the 6,6-dimethylbicyclo[3. 1. 1] heptanols.

\section{EXPERIMENTAL}

All boiling and melting points were uncorrected. IR spectra were recorded on a JASCO IRA-1. Gas chromatography was done with a Shimadzu 4BM-PF using a $2 \mathrm{~m} \times 3 \mathrm{~mm}$ column packed with $3 \%$ OV-225 at $120^{\circ}$ flowing nitrogen, unless otherwise stated. Mass spectra were taken on a Shimadzu GCMS-7000 with the same column in the $\mathrm{GC}$ measurement. Column chromatography was performed with silicic acid. Solutions were dried over $\mathrm{MgSO}_{4}$, and evaporations were carried out at $35^{\circ}$ in vacuo. $n$-Hexane, ethyl acetate, tetrahydrofuran are abbreviated as $\mathrm{H}$, EtOAc, and THF in this section. The PMR data of the compounds in the table are omitted. For the specific rotations and PMR spectra, refer to the footnotes.

$(+)$-cis-Verbenol $(\mathbf{1}),(+)$-trans-verbenol $(2)$ and $(+)$ verbenone (14). These compounds were synthesized from $(+)$ - $\alpha$-pinene, $[\alpha]_{D}+46.9^{\circ}$ (neat), according to Mori et al. ${ }^{\mathrm{B})}$ The physical data agreed with the reported values, except for the specific rotations. (+)cis-Verbenol (1), $\operatorname{mp} 69 \sim 70^{\circ} ; \quad[\alpha]_{D}+9.6^{\circ} \quad(c=0.94$, $\left.\mathrm{CHCl}_{3}\right),-4.0^{\circ}(c=0.87)$. (+)-trans-Verbenol (2), $103^{\circ} \%$ $18 \mathrm{~mm} \mathrm{Hg} ;[\alpha]_{\mathrm{D}}+130.0^{\circ}\left(c=1.0, \mathrm{CHCl}_{3}\right),+120.2^{\circ}(c=$ 1.2); $\left[c f\right.$. its acetate, $[\alpha]_{\mathrm{D}}+153.0^{\circ}\left(c=0.97, \mathrm{CHCl}_{3}\right)$, $\left.+147.0^{\circ}(c=2.0)\right] . \quad(+)$-Verbenone $(14),[\alpha]_{\mathrm{D}}+240.1^{\circ}$ $\left(c=1.2, \mathrm{CHCl}_{3}\right),+236.8^{\circ}(c=1.1)$.

(+)-cis-Verbanone (15). (+)-Verbenone (14) (1.8 g) in methanol $(50 \mathrm{ml})$ was hydrogenated in the presence of $5 \%$ palladium-carbon at r.t. for $1 \mathrm{hr}$. After chromatography $(\mathrm{H}: \mathrm{EcOAc}=10: 1)$, pure $(+)$-cis-verbanone (15) was given, $[\alpha]_{D}+48.5^{\circ}(c=1.2)$; IR (film): $1705 \mathrm{~cm}^{-1}$; PMR: $1.01(3 \mathrm{H}, \mathrm{s}), 1.17(3 \mathrm{H}, \mathrm{d}, J=7.0)$, $1.36(3 \mathrm{H}, \mathrm{s}) ; \mathrm{GC}: t_{\mathrm{R}} 6.6 \mathrm{~min} ; \mathrm{MS}: m / e 152\left(\mathrm{M}^{+}\right.$, $\mathrm{C}_{10} \mathrm{H}_{18} \mathrm{O}$ ), $137\left(\mathrm{M}^{+}-15\right), 85$ (Base peak).

$(+)$-Neoisoverbanol (3). Lithium aluminum hydride was added in excess to a solution of 15 in ether, and stirred the mixture at r.t. overnight. The ether was removed after usual treatment. The resulting residue was recrystallized from $\mathrm{H}$ to give $(+)$-neoisoverbanol (3), $\operatorname{mp} 68 \sim 69.5^{\circ} ;[a]_{\mathrm{D}}+9.0^{\circ} \quad(c=0.48) ;$ IR 
$(\mathrm{KBr}): 3320 \mathrm{~cm}^{-1}$; GC: $t_{\mathrm{R}} 4.8 \mathrm{~min} ; \mathrm{MS}: \mathrm{m} / \mathrm{e} 154\left(\mathrm{M}^{+}\right.$, $\left.\mathrm{C}_{10} \mathrm{H}_{18} \mathrm{O}\right), 139\left(\mathrm{M}^{+}-15\right), 85$ (Base peak).

(+)-Isoverbanol (4). Hydrogen gas was passed through a cyclohexane $(20 \mathrm{ml})$ solution of $(+)$-transverbenol (2) $(300 \mathrm{mg})$ in the presence of platinum oxide $(40 \mathrm{mg})$ at r.t. for $30 \mathrm{~min}$. A residue of the reaction mixture was recrystallized from $\mathrm{H}$ to give $(+)$-isoverbanol (4), mp 61 64, $[\alpha]_{\mathrm{D}}+43.8^{\circ} \quad(c=0.5) ;$ IR $(\mathrm{KBr}): 3280 \mathrm{~cm}^{-1}$; GC: $t_{\mathrm{R}} 5.5 \mathrm{~min}$; MS: $m / e 154\left(\mathrm{M}^{+}\right.$, $\left.\mathrm{C}_{10} \mathrm{H}_{18} \mathrm{O}\right), 139\left(\mathrm{M}^{+} \ldots 15\right), 85$ (Base peak).

3ק-Bromonopinone (18). Bromine $(3 \mathrm{ml})$ was added to a solution of $(+)$-nopinone (17) $(6.2 \mathrm{~g}),[\alpha]_{D}+12.3^{\circ}$ $(c=0.95)$, in ether $(120 \mathrm{ml})$, and the mixture was stirred at r.t. for $30 \mathrm{~min}$. After the reaction was completed by refluxing for $30 \mathrm{~min}$, the ether solution was washed with $\mathrm{NaHSO}_{3}$ and $\mathrm{NaHCO}_{3}$ solutions. Removal of the solvent gave a crude crystal which included a trace amount of $3 \alpha$-bromonopinone (18'). Recrystallization of the crude crystal from ether afforded $3 \beta$-bromonopinone $(18), \mathrm{mp} 111 \sim 112^{\circ} ;[\alpha]_{D}-9.8^{\circ}(c=0.92) ; \mathrm{IR}$ $(\mathrm{KBr}): 1710 \mathrm{~cm}^{-1}$; PMR: $0.88(3 \mathrm{H}, \mathrm{s}), 1.37(3 \mathrm{H}, \mathrm{s})$, $1.72(1 \mathrm{H}, \mathrm{d}, J=10.0), 2.0 \sim 3.2(5 \mathrm{H}, \mathrm{m}), 4.82(1 \mathrm{H}$, double quartet, $J=1.0,8.0,10.5): 3 \alpha$-Bromonopinone (18'), mp 68 69 ; $[\alpha]_{\mathfrak{D}}+125^{\circ}(c=0.94) ; \operatorname{IR}(\mathrm{KBr})$; $1700 \mathrm{~cm}^{-1}$; PMR: $0.85(3 \mathrm{H}, \mathrm{s}), 1.38(3 \mathrm{H}, \mathrm{s}), 4.39(1 \mathrm{H}$, double $\mathrm{d}, J=3.5,7.5)$.

(+)-trans-Verbanone (20). A mixture of the bromonopinone (18) (2.7 g), DBU (2.7 g) and dimethylformamide $(30 \mathrm{ml})$ was stirred at $160^{\circ}$ for $3 \mathrm{hr}$ in argon atmosphere. The reaction mixture was poured into water, and extracted with ether. Evaporation of the ether gave a residue. Column chromatography $(\mathrm{H}$ : $E t O A c=10: 1)$ of the residue afforded crude apoverbenone (19), To an ether solution of $\mathrm{Me}_{2} \mathrm{CuLi}$ [prepared from cuprous iodide $(4.2 \mathrm{~g})$ in ether $(20 \mathrm{ml})$ and $5 \%$ methyl lithium in ether $(28 \mathrm{ml})]$, the crude $19(2.8 \mathrm{~g})$ was added. The mixture was stirred at r.t. for $2 \mathrm{hr}$ in argon gas, and the reaction mixture was washed with water and evaporated to give a crude $\mathbf{2 0}$ which afforded pure $(+)$-trans-verbanone $(20)(1.6 \mathrm{~g})$ by column chromatography (H: EtOAc $=10: 1),[\alpha]_{D}+28.3^{\circ}(c=0.99)$; IR(film): $1710 \mathrm{~cm}^{-1}$; PMR: $0.84(3 \mathrm{H}, \mathrm{s}), 1.05(3 \mathrm{H}, \mathrm{m})$, $1.32(3 \mathrm{H}, \mathrm{s})$; GC: $t_{\mathrm{R}} 6.2 \mathrm{~min}$; MS: $m / e 152\left(\mathrm{M}^{+}\right.$, $\left.\mathrm{C}_{10} \mathrm{H}_{10} \mathrm{O}\right), 137\left(\mathrm{M}^{+}-15\right), 83$ (Base peak).

(-)-Neoverbanol (5). The verbanone (20) (215 mg) in ether $(20 \mathrm{ml})$ was reduced with $\mathrm{LiAlH}_{4}$ at r.t. for $2 \mathrm{hr}$. Excess $\mathrm{LiAlH}_{4}$ was decomposed with water and $15 \%$ $\mathrm{NaOH}$ solution. A crude crystal $(200 \mathrm{mg})$ after removal of the ether was refined by recrystallization from $\mathrm{H}$ to obtain pure (-)-neoverbanol (5), mp $76.5 \sim 77^{\circ}$; $[\alpha]_{\mathrm{D}}-16.5^{\circ} \quad(c=1.1) ; \mathrm{IR}(\mathrm{KBr}): 3300 \mathrm{~cm}^{-1} ; \mathrm{GC} ; t_{\mathrm{R}}$ $5.0 \mathrm{~min}$; MS: $m / e 154\left(\mathrm{M}^{+}, \mathrm{C}_{10} \mathrm{H}_{18} \mathrm{O}\right), 139\left(\mathrm{M}^{+}-15\right)$, 85 (Base peak).
(+)-Verbanol (6). A solution of $20(497 \mathrm{mg})$ in isopropanol $(1 \mathrm{ml})$ was mixed to aluminum isopropoxide which was prepared from aluminum foil $(178 \mathrm{mg})$ and isopropanol $(5 \mathrm{ml})$ in the presence of $\mathrm{HgCl}_{2}(10 \mathrm{mg})$ (refluxing for $2 \mathrm{hr}$ ). The reaction continued for $18 \mathrm{hr}$ distillating the acetone. Termination of the reaction was determined by TLC, i.e., two spots due to 5 and 6 were gradually converted to almost one spot corresponding to 6 after $18 \mathrm{hr}$. The solution was treated with $1 \mathrm{~N}-\mathrm{HCl}$ and extracted with ether. Concentration of the ether gave a residue. The residue was column-chromatographed $(\mathrm{H}: \mathrm{EtOAc}=7: 1)$ to give

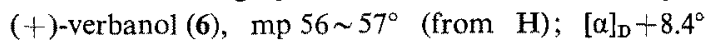
$(c=0.48) ; \mathrm{IR}(\mathrm{KBr}): 3240 \mathrm{~cm}^{-1} ; \mathrm{GC}: t_{R} 5.8 \mathrm{~min} ; \mathrm{MS}$ : $m / e 154\left(\mathrm{M}^{+}, \mathrm{C}_{10} \mathrm{H}_{18} \mathrm{O}\right), 139\left(\mathrm{M}^{+}-15\right), 85$ (Base peak).

3-Methylenenopinone (22). Ethanol $(1.1 \mathrm{ml})$ and sodium metal $(1.2 \mathrm{~g})$ were added successively to a solution of nopinone (17) $(7.5 \mathrm{~g})$ and ethyl formate $(6.1 \mathrm{~g})$ in ether $(110 \mathrm{ml})$, and stirred for $2 \mathrm{hr}$. At this time, the sodium was perfectly consumed, and a brown precipitation was formed. By addition of water, the ether and water layers were separated. The water layer was acidified with $1 \mathrm{~N}-\mathrm{HCl}$, and extracted with ether. This ether solution produced a yellow crystal of hydroxymethylenenopinone (21), PMR: $7.17(1 \mathrm{H}$, broad s), after evaporation. The crude crystal was immediately used to the next reaction. To a solution of $21(10.8 \mathrm{~g})$ in ether $(200 \mathrm{ml}), \mathrm{K}_{2} \mathrm{CO}_{3}(42.4 \mathrm{~g})$ and $37 \%$ formaldehyde solution $(43 \mathrm{ml})$ were added. The reaction at r.t. was terminated after $2 \mathrm{hr}$. Evaporation of the ether gave a residue, and the residue was columnchromatographed $(\mathrm{H}: \mathrm{EtOAc}=5: 1)$ to give 3-methylenenopinone (22), (7.8 g), $[\alpha]_{\mathrm{D}}+23.5^{\circ}(c=1.1) ;$ IR (film): $1705,1610 \mathrm{~cm}^{-1}$, PMR: $0.89(3 \mathrm{H}, \mathrm{s}), 1.35(3 \mathrm{H}$, s), $5.37(1 \mathrm{H}, \mathrm{m}), 6.31(1 \mathrm{H}, \mathrm{m})$; GC: $t_{\mathrm{R}} 5.1 \mathrm{~min}$; MS: $m / e 150\left(\mathrm{M}^{+}, \mathrm{C}_{10} \mathrm{H}_{14} \mathrm{O}\right), 135\left(\mathrm{M}^{+}-15\right), 107,83$ (Base peak).

38-Methylnopinone (23). Hydrogen gas was bubbled into a mixture of $22(1.5 \mathrm{~g})$, platinum oxide $(100 \mathrm{mg})$ and methanol at r.t. for $30 \mathrm{~min}$. Column chromatography $(\mathrm{H}: \mathrm{EtOAc}=7: 1)$ of the concentrate gave $3 \beta$ methylnopinone (23) $(1.3 \mathrm{~g})$ with a trace amount of $3 \alpha$-methylnopinone (24). $3 \beta$-Methylnopinone (23), IR (film): $1720 \mathrm{~cm}^{-1}$; PMR: $0.70(3 \mathrm{H}, \mathrm{s}), 1.12(3 \mathrm{H}, \mathrm{d}$, $J=6.0), 1.29(3 \mathrm{H}, \mathrm{s}), 1.68(1 \mathrm{H}, \mathrm{d}, J=9.0)$; GC: $t_{\mathrm{R}}$ $6.3 \mathrm{~min}$; MS: $m / e 152\left(\mathrm{M}^{+}, \mathrm{C}_{10} \mathrm{H}_{18} \mathrm{O}\right), 137\left(\mathrm{M}^{+}-15\right)$, $109,95,83$ (Base peak).

(-)-3B-Methyl-cis-nopinol (7). The usual $\mathrm{LiAlH}_{4}$ reduction of $23(520 \mathrm{mg}$ ) afforded a crude alcohol. Column chromatography of the crude alcohol separately afforded $3 \beta$-methyl-cis-nopinol (7) $(497 \mathrm{mg})$ and $3 \alpha$-methyl isomer (10) $(29 \mathrm{mg})$ whose origin was the contaminated $3 \alpha$-methylnopinone (24). 3 3 -Methyl-cisnopinol $(7),[\alpha]_{\mathbb{D}}-0.8^{\circ}(c=1.0)$; IR (film): $3400 \mathrm{~cm}^{-1}$; 
GC (PEG 20M, 120 $) ; t_{\mathrm{R}} 8.0 \mathrm{~min}$; MS: $m / e 154\left(\mathrm{M}^{+}\right.$, $\left.\mathrm{C}_{10} \mathrm{H}_{18} \mathrm{O}\right), 139\left(\mathrm{M}^{+}-15\right), 121,85$ (Base peak).

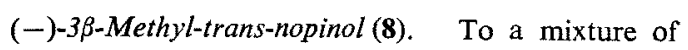
THF $(3 \mathrm{ml})$ and liquid ammonia $(9 \mathrm{ml}), 3 \beta$-methylnopinone (23) (402 $\mathrm{mg}$ ) was added at $-78^{\circ}$, and stirred. Furthermore, ammonium chloride $(700 \mathrm{mg})$ and lithium metal $(20 \mathrm{mg})$ were added to the solution. The cooling bath was removed and allowed to stand to r.t. to release the ammonia. After water and ether were added to the solution, the ether was dried and removed to give a residue which showed two main spots and several minor spots in a TLC analysis. Components corresponding to the two spots were separated by column chromatography $(\mathrm{H}: \mathrm{EtOAc}=$ 7:1). One of them was (-)-3 $\beta$-methyl-trans-nopinol (8) $(296 \mathrm{mg}), \mathrm{mp} 44 \sim 46^{\circ} ;[\alpha]_{\mathrm{D}}-62.6^{\circ}(c=0.48)$; IR (KBr): $3240 \mathrm{~cm}^{-1}$; GC (PEG 20M, 120 $): t_{\mathrm{R}} 9.2 \mathrm{~min}$; MS: $m / e 154\left(\mathrm{M}^{+}, \mathrm{C}_{10} \mathrm{H}_{13} \mathrm{O}\right), 139\left(\mathrm{M}^{+}-15\right), 85$ (Base peak). Another component was 7 .

3a-Methylnopinone (24). To a solution of nopinone $(17)(2.0 \mathrm{~g})$ in THF $(5 \mathrm{ml})$, LDA [prepared from $15 \% n$-butyllithium in hexan $(8.8 \mathrm{ml})$, diisopropylamine $(2.0 \mathrm{ml})$ and THF $(5 \mathrm{ml})]$ was added in argon atmosphere under ice-cooling. The temperature was raised to r.t., and methyl iodide $(0.94 \mathrm{ml})$ was added to the reaction mixture. After $30 \mathrm{~min}$ the mixture was poured into a saturated $\mathrm{NH}_{4} \mathrm{Cl}$ solution, and extracted with ether. The residue of the extract was chromatographed $(\mathrm{H}: \mathrm{EtOAC}=10: 1)$ to afford 30-methylnopinone (24) $(1.4 \mathrm{~g}),[\alpha]_{\mathrm{D}}+29.0^{\circ}(c=1.0)$; IR (film): $1710 \mathrm{~cm}^{-1}$; PMR: $0.90(3 \mathrm{H}, \mathrm{s}), 1.31(3 \mathrm{H}, \mathrm{d}, J=7.0)$, $1.33(3 \mathrm{H}, \mathrm{s})$; GC: $t_{\mathrm{R}} 6.0 \mathrm{~min}$; MS: $m / e 152\left(\mathrm{M}^{+}\right.$, $\left.\mathrm{C}_{10} \mathrm{H}_{16} \mathrm{O}\right), 137\left(\mathrm{M}^{+}-15\right), 109,83$ (Base peak). This chromatography also afforded the unchanged nopinone (17) $(555 \mathrm{mg})$ and 3,3-dimethylnopinone ( $23 \mathrm{mg}$ ), PMR: $0.84(3 \mathrm{H}, \mathrm{s}), 1.25(3 \mathrm{H}, \mathrm{s}), 1.30(3 \mathrm{H}, \mathrm{s}), 1.32$ $(3 \mathrm{H}, \mathrm{s})$.

(+)-3a-Methyl-cis-nopinol (9). 3a-Methylnopinone (24) gave $(+)$-3a-methyl-cis-nopinol (9) by the usual reduction with $\mathrm{LiAlH}_{4}, \mathrm{mp} 89 \sim 91.5^{\circ}$ (from $\mathrm{H}$ ); $[\alpha]_{D}$ $+45.4^{\circ}(c=0.46)$; IR $(\mathrm{KBr}): 3280 \mathrm{~cm}^{-1}$; GC: $t_{\mathrm{n}} 3.5$ min; $\mathrm{MS}: \operatorname{m} / e \mathrm{e} 54\left(\mathrm{M}^{+}, \mathrm{C}_{10} \mathrm{H}_{18} \mathrm{O}\right), 139\left(\mathrm{M}^{+}-15\right), 136$ $\left(\mathrm{M}^{+}-18\right), 121,97,85$ (Base peak).

(+)-3-Methylene-cis-nopinol (11) and (-)-3-methylene-trans-nopinol (12). To a solution of aluminum isopropoxide in isopropanol [prepared from aluminum foil $(107 \mathrm{mg}), \mathrm{HgCl}_{2}(6 \mathrm{mg})$ and isopropanol $(3 \mathrm{ml})$ ], 3-methylenenopinone (22) $(550 \mathrm{mg})$ in isopropanol $(1 \mathrm{ml})$ was added, and refluxed for $15 \mathrm{hr}$, distillating the resulting acetone. The reaction mixture was poured into $1 \mathrm{~N}-\mathrm{HCl}$, and extracted with ether. An oily residue of the ether layer was column-chromatographed $(\mathrm{H}: \mathrm{EtOAc}=10: 1)$ to provide $11(87 \mathrm{mg})$ and 12 (322 mg). (+)-3-Methylene-cis-nopinol (11), mp 59.5 $\sim 61.5^{\circ},[\alpha]_{\mathrm{D}}+76.6^{\circ}(c=1.1) ; \operatorname{IR}(\mathrm{KBr}): 3370,1640$, $900 \mathrm{~cm}^{-1} ; \mathrm{GC}: t_{\mathrm{R}} 3.9 \mathrm{~min}$; MS: $m / e$ $137\left(\mathrm{M}^{+}-15\right), 119,91$ (Base peak). (-)-3-Methylenetrans-nopinol (12), $[\alpha]_{\mathrm{D}}-52.5^{\circ} \quad(c=1.0)$; IR (film): $3380,1630,895 \mathrm{~cm}^{-1}$; GC: $t_{\mathrm{R}} 4.7 \mathrm{~min}$; MS: $m / e$ $\left(\mathrm{M}^{+}, \mathrm{C}_{10} \mathrm{H}_{18} \mathrm{O}\right), 137\left(\mathrm{M}^{+}-15\right), 134,119,109,91,85$ (Base peak).

3a-Hydroxymethyl-trans-nopinol (25). A solution of $12(900 \mathrm{mg})$ in THF $(2 \mathrm{ml})$ was added to a solution of borane in THF [prepared by addition of $\mathrm{BF}_{3}$-etherate $(2.5 \mathrm{ml})$ of $\mathrm{NaBH}_{4}(475 \mathrm{mg})$ suspension in THF $\left.(10 \mathrm{ml})\right]$ under ice-cooling, and stirred at r.t. for $1 \mathrm{hr}$. After addition of $3 \mathrm{~N}-\mathrm{NaOH}(2.3 \mathrm{ml})$ and $30 \%-\mathrm{H}_{2} \mathrm{O}_{2}(2.3 \mathrm{ml})$ the mixture was refluxed for $1 \mathrm{hr}$. Water and enough ether were added. The ether layer was dried and concentrated. The resulting residue was chromatographed $(\mathrm{H}: \mathrm{EtOAC}=2: 1$ after $3: 1)$ to give $3 \alpha$-hydroxymethyltrans-nopinol (25) $(593 \mathrm{mg}$ ), mp 37 38.5 (from $\mathrm{H}$ ); $[\alpha]_{D}-9.0^{\circ} \quad(c=0.98):$ IR (nujol): $3410,3160 \mathrm{~cm}^{-1}$ : PMR $0.90(3 \mathrm{H}, \mathrm{s}), 1.26(3 \mathrm{H}, \mathrm{s}), 3.6 \sim 4.0(2 \mathrm{H}$, broad $\mathrm{m}), 4.50(1 \mathrm{H}$, broad d, $J=8.0)$; GC and MS were taken using diacetate of $25, \mathrm{t}_{\mathrm{R}} 9.5 \mathrm{~min} ; \mathrm{m} / \mathrm{e} 239\left(\mathrm{M}^{+}-15\right)$, $213\left(\mathrm{M}^{+}-40\right), 211,194\left(\mathrm{M}^{+}-60\right), 152,134,85,43$ (Base peak).

Monophenylsulfide of 25 (26). Tributylphosphine $(2.7 \mathrm{ml})$ was added to a solution of $25(478 \mathrm{mg})$ in pyridine $(2 \mathrm{ml})$ and diphenyl disulfide $(2.2 \mathrm{~g})$ in argon atmosphere, and stirred at r.t. overnight. The pyridine was removed at $r$. t. with a vacuum pump and the resulting residue was subjected to column chromatography $(\mathrm{H}$ : $E$ tOAc $=3: 1$ after $7: 1)$ to obtain 26, $\mathrm{mp} 63 \sim 65^{\circ}$ (from $\mathrm{H}) ;[\alpha]_{\mathrm{D}}-51.8^{\circ}(c=0.54)$; PMR: $0.86(3 \mathrm{H}, \mathrm{s})$, $1.21(3 \mathrm{H}, \mathrm{s}), 2.91(1 \mathrm{H}$, double d, $J=6.0,11.5), 3.35(1 \mathrm{H}$, double d, $J=8.0,11.5), 4.38(1 \mathrm{H}$, broad d, $J=7.0)$, $7.1 \sim 7.6(5 \mathrm{H}, \mathrm{m}) ; \mathrm{MS}: m / e 262\left(\mathrm{M}^{+}, \mathrm{C}_{10} \mathrm{H}_{22} \mathrm{OS}\right), 244$ $\left(\mathrm{M}^{+}-18\right), 177,153,110$ (Base peak).

(-)-3a-Methyl-trans-nopinol (10). The monophenylsulfide (26) $(324 \mathrm{mg})$ was subjected to Birch reduction by the same procedure performed to get compound 8 [THF $(4 \mathrm{ml})$, liquid ammonia $(8 \mathrm{ml})$, lithium metal $(20 \mathrm{mg})$, at $-78^{\circ}$ for $2 \mathrm{hr}$. The resulting crude crystal was column-chromatographed $(\mathrm{H}: \mathrm{EtOAc}=$ 7:1) to afford pure (-)-3a-methyl-trans-nopinol (10), $\mathrm{mp} 47 \sim 48.5^{\circ}$ (from $\left.\mathrm{H}\right) ;[\alpha]_{\mathrm{D}}-19.2^{\circ} \quad(c=1.54)$; IR $(\mathrm{KBr}): 3280 \mathrm{~cm}^{-1}$; GC: $t_{\mathrm{R}} 5.5 \mathrm{~min}$; MS: $m / e$ $\left(\mathrm{M}^{+}, \mathrm{C}_{10} \mathrm{H}_{18} \mathrm{O}\right), 139\left(\mathrm{M}^{+}-15\right), 121,111,93,85$ (Base peak).

Acknowledgments. The authors wish to express their appreciation to Mr. Y. Isogai and Dr. H. Ohtani, Mitsubishi Chemical Industries Co., for the use of the PMR apparatus. Acknowledgment is given to Dr. T. Kobayashi, Takasago Perfumery Co., for the gift of verbenone. 


\section{REFERENCES}

1) L. M. Roth and E. R. Willis, Am. Midl. Nat., 47, 66 (1952).

2) C. J. Persoons, P. E. J. Verwiel, E. Talman and F. J. Ritter, J. Chem. Ecol., 5, 221 (1979).

3) W.S. Bowers and W. G. Bodenstein, Nature, 232, 259 (1971).

4) C. Nishino, T. R. Tobin and W. S. Bowers, Appl. Ent. Zool., 12, 287 (1977).

5) C. Nishino, T. R. Tobin and W. S. Bowers, unpublished data.

6) D. S. Noyce and D. B. Denney, J, Am. Chem. Soc. 72, 5743 (1950).

7) G. Ourrison and A. Rassat, Tetrahedron Letters, $1960,16$.

8) K. Mori, N. Mizumachi and M. Matsui, Agric. Biol. Chem., 40, 1611 (1976). K. Mori, ibid., 40, 415 (1976).

9) Y. Bessiere-Chretien and G. Grison, Bull. Soc.
Chim. Fr., 1970, 3103.

10) Y. Bessière-Chrétien and B. Meklate, ibid, 1971, 2591.

11) I. Nakagawa and T. Hata, Tetrahedron Letters, $1975,1409$.

12) A. F. Regan, Tetrahedron, 25, 3801 (1969). M. Mühlstädt, M. Herrmann and A. Zschunke, ibid., 24, 1611 (1968).

13) H. O. House "Modern Synthetic Reactions," second ed., W. A. Benjamin, Inc., Menlo Park, Calif., 1972, pp. 586-595.

14) G. E. Hawkes, D. Leibfritz, D. W. Roberts and J. D. Roberts, J. Am. Chem. Soc., 95, 1659 (1973).

15) K.-T. Liu, J. Chinese Chem. Soc., 23, 1 (1976).

16) M. A. Cooper, J. R. Salmon, D. Whittaker and U. Scheidegger, J. Chem. Soc. $(B), 1967,1259$.

17) E-C. Sen and R. A. Jones, Tetrahedron, 28, 2871 (1972).

18) J. Paasivirta and J. Korvola, Suomen Kemistilehti $B, 46,259$ (1973). 